\title{
Modeling Bridge Condition Levels in the United States
}

\author{
Denver Tolliver and Pan Lu \\ Upper Great Plains Transportation Institute, North Dakota State University, Fargo, ND58105, USA
}

\begin{abstract}
The objectives of this paper are to (1) quantify the effects of age and other key factors on bridge deterioration rates, and (2) provide bridge managers with strategic forecasting tools. A model for forecasting substructure conditionisestimated from the National Bridge Inventory that includes the effects of bridge material, design load, structural type, operating rating, average daily traffic, water, and the state where the bridge is located. Bridge age is the quantitative independent variable. The relationship between age and substructure condition is a fourth-order polynomial. Some of the key findings are: (1) a bridge substructure is expected to lose from 0.52 to 0.11 rating points per decade as it ages from 10 to 70 years; (2) levels of deterioration increase significantly as the material changes from concrete, to steel, to timber; (3) slab bridges have lower levels of deterioration than other structures; (4) bridges that span water have lower condition ratings; (5) bridges with higher operating ratingshave higher condition ratings; and (6) substructure condition ratings vary significantly among states.
\end{abstract}

Key words: Highway bridges, bridge condition levels, bridge deterioration rates, statistical forecasting models.

\section{Introduction}

Nearly 600,000 bridges located on public roads in the United States are greater than 6.1 meters or 20 feet in length [1]. As stipulatedin the National Bridge Inspection Standards, bridges of these lengths are inspected at least once every two years. During these inspections, the conditions of the three major bridge components (deck, superstructure, and substructure) are rated using a standard scale developed by Federal Highway Administration, which includes eight interim levels between excellent and failure (Table 1). A composite score is assigned by evaluating the severity of the deterioration of individual bridge elements and assessing the extent to which the deterioration or disrepair is widespread throughout the entire component. A rating of 4 or less indicates poor condition or worse and typically results in a bridge being classified as structurally deficient.

Bridge condition assessments and other vital statistics are compiled in the National Bridge Inventory (NBI). According to the NBI, approximately $14 \%$ of

Corresponding author: $\mathrm{Pan} \mathrm{Lu}, \mathrm{PhD}$, research fields: GIS applications in transportation; transportation infrastructural management system; freight transportation; environmental analysis; multi-mode transportation. E-mail: pan.lu@ndsu.edu. the highway bridges in the United States longer than 6.1 meters are classified as structurally deficient (Fig. 1). A bridge labeled structurally deficient is not necessarily unsafe or likely to collapse. However, the bridge will incur additional expenses for increased inspection, spot maintenance, and repairs in order to remain in service. Moreover, the maximum gross vehicle weight may be restricted to less than the legal limit. An additional $15 \%$ of highway bridges are classified as functionally obsolete, due to substandard lane or roadway widths and other geometric shortcomings. Because of growingdeterioration and obsolescence, the American Society of Civil Engineers [2] has given America's bridges a grade of $\mathrm{D}$ on scale from $\mathrm{A}$ to $\mathrm{E}$.

According to the NBI, more than one billion vehicles utilize functionally obsolete or structurally deficient bridges in the United States each day. However, this utilization rate does not consider traffic that is diverted from or routed around substandard bridges and the additional distances and travel times required. The average distance to bypass functionally obsolete or structurally deficient bridges is 20 kilometers, suggesting that posted, deteriorated, or substandard bridges may be impeding commerce and mobility. 
Table 1 Condition ratings used in the national bridge inventory.

\begin{tabular}{|c|l|l|}
\hline Code & \multicolumn{1}{|c|}{ Meaning } & \multicolumn{1}{|c|}{ Description } \\
\hline 9 & Excellent & \\
\hline 8 & Very Good & No problems noted. \\
\hline 7 & Good & Some minor problems. \\
\hline 6 & Satisfactory & Structural elements show some minor deterioration. \\
\hline 5 & Fair & Primary structural elements are sound but may have minor section loss, cracking, spalling or scour. \\
\hline 4 & Poor & Advanced section loss, deterioration, spalling or scour. \\
\hline 3 & Serious & $\begin{array}{l}\text { Loss of section, deterioration, spalling or scour has seriously affected primary structural components. } \\
\text { Local failures are possible. Fatigue cracks in steel or shear cracks in concrete may be present. }\end{array}$ \\
\hline 2 & Critical & $\begin{array}{l}\text { Advanced deterioration of primary structural elements. Fatigue cracks in steel or shear cracks in } \\
\text { concrete may be present or scour may have removed substructure support. Unless closely monitored it } \\
\text { may be necessary to close the bridge until corrective action is taken. }\end{array}$ \\
\hline 1 & Imminent Failure & $\begin{array}{l}\text { Major deterioration or section loss present in critical structural components or obvious vertical or } \\
\text { horizontal movement affecting structure stability. Bridge is closed to traffic, but with corrective } \\
\text { action, may put back in light service. }\end{array}$ \\
\hline 0 & Failed & Out of service -- beyond corrective action. \\
\hline
\end{tabular}

United States Department of Transportation: Recording and Coding Guide for the Structure Inventory and Appraisal of the Nation's Bridges, Washington, D.C., 1995, p. 38.

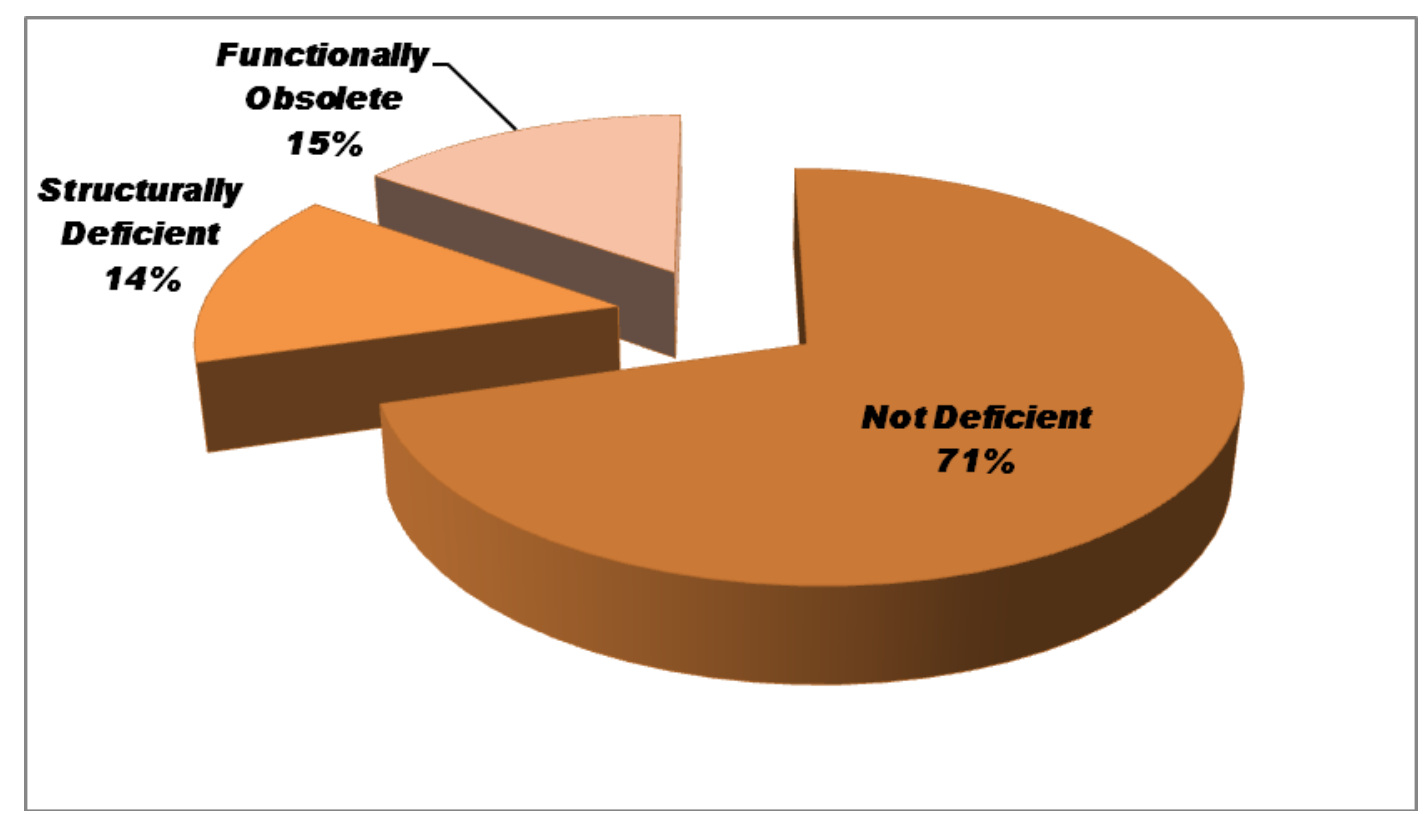

Fig. 1 Status of highway bridges in the United States.

Computed from the 2009 National Bridge Inventory, including bridges $>6.1 \mathrm{~m}$ in length, with culverts excluded.

The objectives of this paper are two folds: (1) to quantify the effects of key factors on bridge deterioration rates and (2) to provide bridge managers with forecasting tools to help them project condition ratings as a function of age, bridge type, material, and geographic and jurisdictional location. In the United States, the Federal Highway Administration has developed the National Bridge Investment Analysis
System (NBIAS) to analyze and forecast bridge conditions. The NBIAS analyzes deficiencies at the level of individual bridge elements (such as beams, trusses, girders, cables, etc.) using the National Bridge Inventory. A probabilistic method of modelling bridge deterioration is used in which transition probabilities are used to project the likelihood that a bridge element will deteriorate from its current condition state to a 
lower condition level during a future interval. The NBIAS assumes that the probability of a bridge element deteriorating from its current condition to the next (lower) level is independent of age.

Muchof the research in the area of bridge managementhas focused on predictions derived from Markov Chains using transition probabilities. In these models, the probability that a bridge (or bridge element) will be in a certain condition at time $t_{1}$ is a function of its condition at time $t_{0}$. While useful, Markov Chainsare based on simple, often unrealistic assumptions. (1) The future condition of a bridge is dependent only on its current condition: i.e., the history of bridge deterioration in previous periods is not taken into account. (2) A bridge stays in acondition state for a predefined time. At the end of each time period the bridge either moves to a new state or stays in the same state for another predefined period. (3) The transition probabilities are constant over time.

Less emphasis has been given tolong-term predictive models inwhich future bridge conditions are forecasted from a set of explanatory variables. Nevertheless, in the literature it is possible to find information that age is a key determinant of deterioration [3-5] and otheressential bridge features contribute significantly to bridge deterioration [5-7].
Roughly half of the highway bridges in the United States were constructed prior to 1970 (Fig. 2), so age is a key consideration in bridge analysis. As noted by the United States Department of Transportation [1] if a bridge's age (independent of current condition) has an effect on its deterioration rate "this could create a situation in which bridge investment needs would be clustered in certain time frames rather than distributed more evenly over time. To the extent that such spikes can be anticipated, such information would be very useful in designing system-wide bridge management strategies.'Before describing amodelthat canbe used forstrategic planning, some essentialbridge features are defined: (1) design load, (2) material type, (3) structural type, and (4) operating rating.

\section{Bridge Characteristics}

\subsection{Structural and Material Types}

The National Bridge Inventory classifies bridges into 23 structural categories. As shown in Fig. 3, the most common structural types are stringer (53\%), slab $(17 \%)$, tee-beam $(10 \%)$, and box-beam/girder $(8 \%)$. The remaining 19 categories (which include arch, truss, suspension, frame, and floor-beam/girder structures) comprise $12 \%$ of all bridges. Fig. 4 shows that concrete

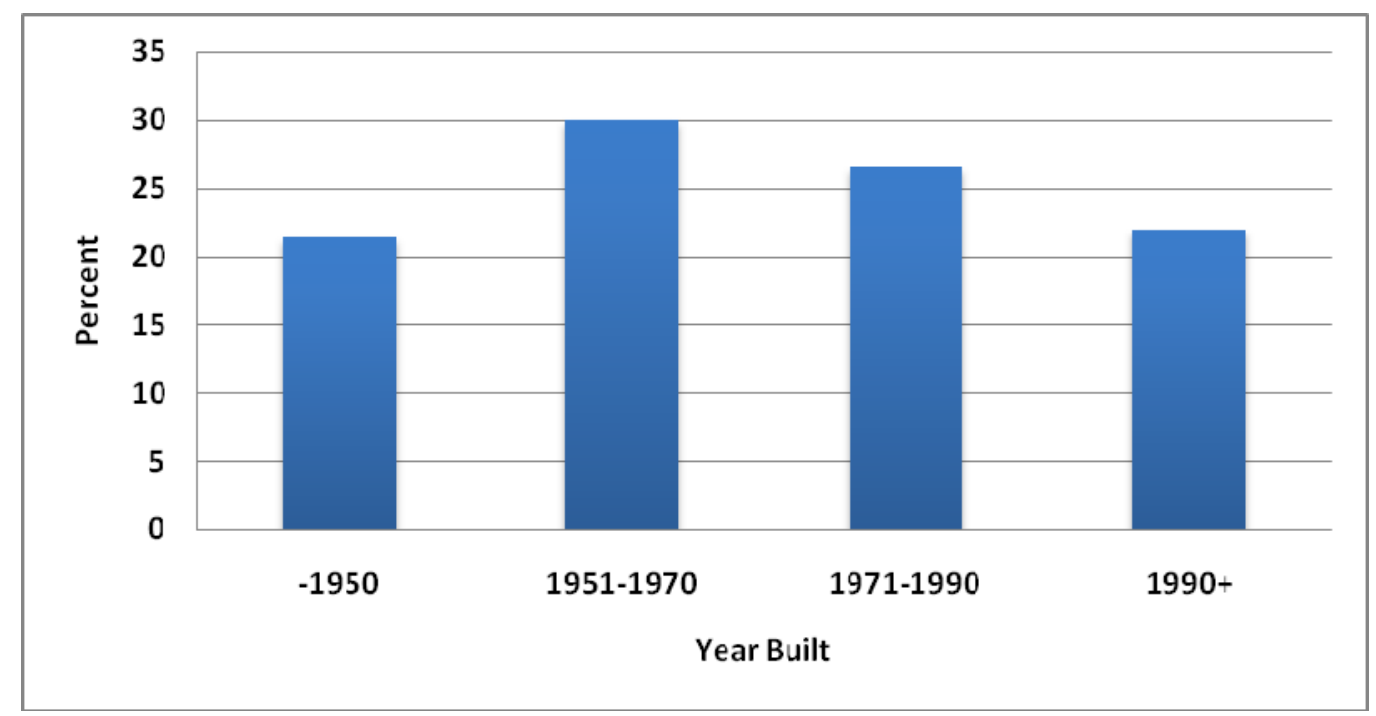

Fig. 2 Year of construction of highway bridges in the United States.

Computed from the 2009 National Bridge Inventory, including bridges $>6.1 \mathrm{~m}$ in length, while excluding culverts. 


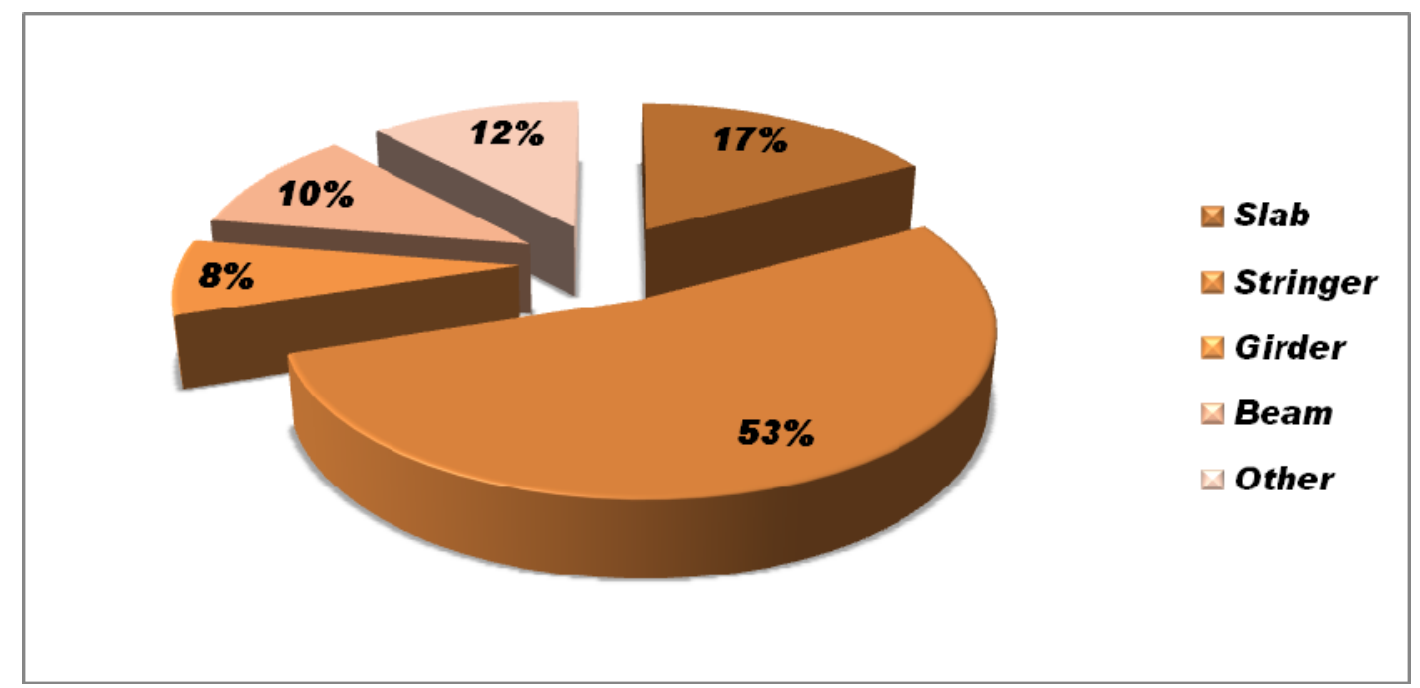

Fig. 3 Classification of highway bridges in the United States by structural type.

Computed from the 2009 National Bridge Inventory, including bridges $>6.1 \mathrm{~m}$ in length, while excluding culverts.

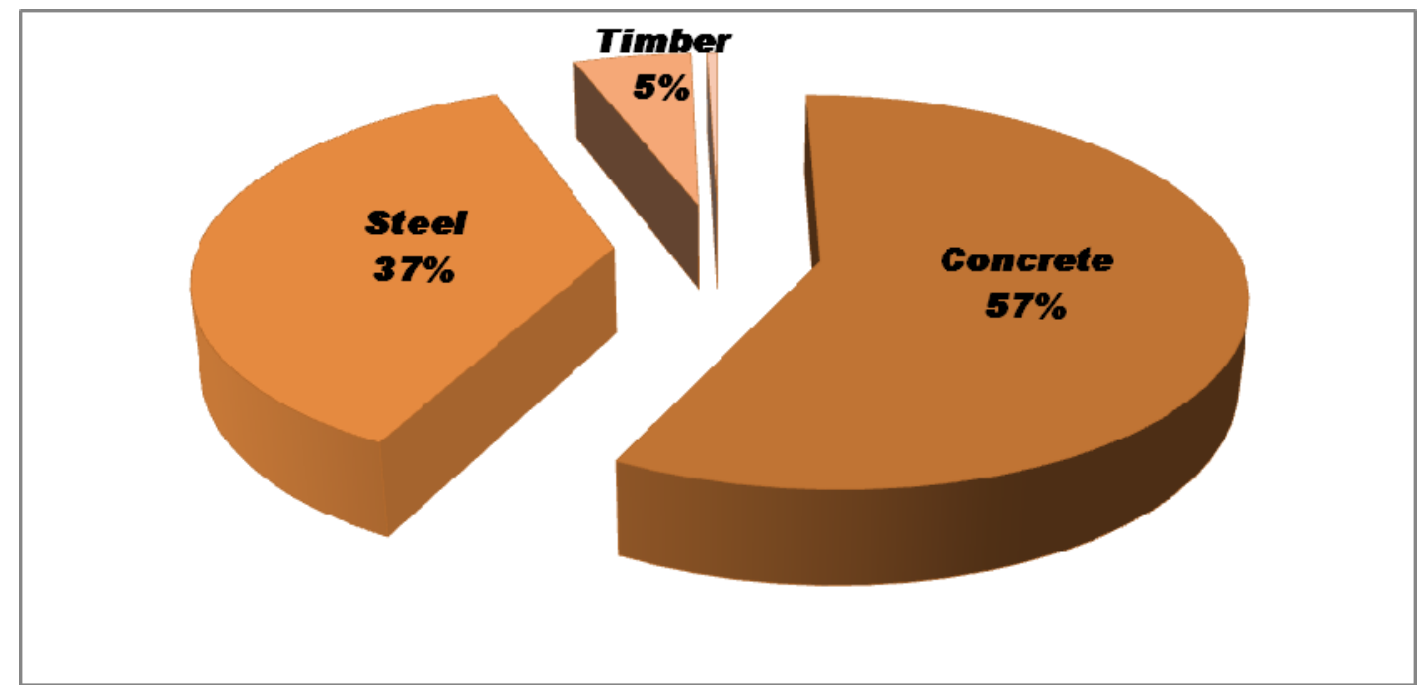

Fig. 4 Highway bridges in the United States by dominant material.

Computed from the 2009 National Bridge Inventory, including bridges $>6.1 \mathrm{~m}$ in length, while excluding culverts.

is the dominant construction material in more than $57 \%$ of the highway bridges in the United States, while steel is the primary material in nearly $37 \%$ of bridges.

\subsection{Design Load}

In the United States, the American Association of State Highway and Transportation Officials (AASHTO) has defined prototypical vehicles for analyzing bridge loads. The alphanumeric codes associated with these vehicles start with "H" or "HS." A prefix of $\mathrm{H}$ denotes a single-unit truck, whereas HS denotes a tractor pulling a semitrailer. For $\mathrm{H}$ bridges, the numeric suffix represents the gross weight in tons of a single-unit truck. For example, H-10 denotes a truck with a gross weight of 10 tons (9.07 metric tons), while H-20 signifies a 20-ton truck. In comparison, the numeric suffix of HS vehicles represents the assumed weight on the first two axle sets of the truck: e.g., the weight distribution to the tractor's steering and driving axles. For example, HS-20 signifies a truck with a total of 20 tons (18.14 metric tons) on the tractor's axles and additional weight on the semitrailer's axle. As shown in Table 2, 49\% of the bridges in the United States are HS-20 or HS $-20^{+}$bridges. 


\subsection{Operating Rating}

The operating rating is the maximum permissible live load that can be placed on a bridge without a special permit. Although the maximum gross vehicle weight on the interstate highway system of the United States is 40 tons, bridge operating ratings may be higher or lower than 40 tons. In fact, $85 \%$ of the bridges in the United States (excluding culverts) have operating ratings of less than 40 tons. Fifty percent of bridges have operating ratings of less than 24.5 tons.

The operating rating provides unique information not necessarily reflected in the design classification. As illustrated in Table 3, H-10, H-15, and H-20 bridges are distributed differently among rating classes. An H-10 bridge with an operating rating $>40$ tons is superior to an $\mathrm{H}-10$ bridge with an operating rating $\leq 20$ tons. In this paper, bridge material, design load, structural type, and operating rating are used to collectively describe the quality dimensions of a bridge. However, due

Table 2 Percentages of highway bridges in the united states designed for specific vehicle loads.

\begin{tabular}{ccc}
\hline Design Load & Number of Bridges & Percent of Bridges \\
\hline H-10 & 11,275 & $2.42 \%$ \\
H-15 & 66,430 & $14.24 \%$ \\
H-20 & 35,701 & $7.65 \%$ \\
HS-15 & 10,127 & $2.17 \%$ \\
HS-20 & 173,581 & $37.20 \%$ \\
HS-20 Plus & 54,131 & $11.60 \%$ \\
HS-25 & 19,728 & $4.23 \%$ \\
Other & 95,628 & $20.49 \%$ \\
\hline
\end{tabular}

Computed from the 2009 National Bridge Inventory, including bridges $>6.1 \mathrm{~m}$ in length, while excluding culverts.

Table 3 Distribution of operating rating by design load category.

\begin{tabular}{lccc}
\hline \multirow{2}{*}{ Operating Rating (Tons) } & \multicolumn{3}{c}{ Percent of Bridges by Design Load } \\
\cline { 2 - 4 } & H-10 & H-15 & H-20 \\
\hline$\leq 20$ & $40.2 \%$ & $6.7 \%$ & $2.7 \%$ \\
$>20$ and $\leq 30$ & $19.9 \%$ & $14.3 \%$ & $4.9 \%$ \\
$>30$ and $\leq 40$ & $28.3 \%$ & $21.8 \%$ & $17.6 \%$ \\
$>40$ & $11.5 \%$ & $57.2 \%$ & $74.9 \%$ \\
\hline
\end{tabular}

Computed from the 2009 National Bridge Inventory, including bridges $>6.1 \mathrm{~m}$ in length, while excluding culverts. to the categorical diversity within the "other structures" group (which includes 19 different types), and the limited number of observations in the "other material" category (which includes only $1 \%$ of the observations), the analysis focuses on the primary bridge materials of concrete, timber, and steel and the four main structural types of stringer, slab, tee-beam, and box girder.

\section{National Bridge Model}

A statistical forecasting model of bridge condition rating is presented in this section of the paper. First, the model form, main effects, and variables are discussed, followed by a summary of the results and parameter estimates. After the estimates are analyzed, methods of forecasting with the model are introduced.

\subsection{Model Form and Main Effects}

In a statistical analysis, separate models can be estimated for each unique category of a dependent variable. However, in doing so, an implicit assumption is made. The assumption is that there are no interactions among categories. While categories of bridges do not interact physically, they are often managed by the same agency; thus, all bridges within a given jurisdiction are subject to a global budget cap.

The approach taken in this study anticipates that the financial resources and attention given to various categories of bridges within a state may not be independent. Consequently, a multivariate model is formulated includingeight effects: bridge type, design load, structural type, operating rating, average daily traffic (ADT group), whether the bridge crosses water, whether the bridge has been reconstructed, and the statein which the bridge is located. The values or levels associated with these effects are summarized in Table 4.

The effects are defined as indicator or indicator variables. To avoid singularity, only $\mathrm{n}-1$ indicator variables are used to represent a given effect. Each category has its own unique intercept. However, the slope (or rate of change in substructure rating with age) is the same after controlling for all effects. 
Table 4 Class level information: national bridge substructure model.

\begin{tabular}{|l|c|l|}
\hline \multicolumn{1}{|c|}{ Class Variable } & Levels & \multicolumn{1}{c|}{ Values } \\
\hline Reconstructed & 2 & 0,1 \\
\hline Bridge Material & 3 & Concrete, Steel, Timber \\
\hline Design Load & 8 & H-10, H-15, H-20, HS-15, HS-20, HS-20+, HS-25, Other \\
\hline Structural Type & 4 & Stringer, Slab, Beam, Girder \\
\hline Operating Rating & 4 & 20 tons, 20.1-30 tons, 30.1-40 tons, $>40$ tons \\
\hline Water Span & 2 & 0,1 \\
\hline ADT & 5 & $<=100 ; 101-1000 ; 1001-5000 ; 5001-19,000 ;>19000$ \\
\hline State & 50 & $\begin{array}{l}\text { AK AL AR AZ CA CO CT DC DE FL GA HI IA ID IL IN KS KY LA MA MD ME MI } \\
\text { MN MO MS MT NC ND NE NH NJ NM NV NY OH OK OR PA RI SC SD TX UT VA } \\
\text { VT WA WI WV WY }\end{array}$ \\
\hline
\end{tabular}

\subsection{Dependent Variable}

Kim and Yoon [5] studied bridge decks and superstructures and found that age is the most significant contributor to the structural deficiency of decks and bridge superstructures in cold regions, followed by the structural characteristics of the bridge and traffic volume. In a complementary way, this paper focuses on bridge substructures - which include elements such as piers, abutments, footings, and foundations that transfer loads from the deck and superstructure to the ground.

Substructure condition (dependent variable of the model) is treated as an integer-scaled variable using the scale shown in Table 1. A change of one unit anywhere on the scale has the same statistical effect.

The interpretation of bridge condition as an integer-scaled variable is acceptable because the purpose of this study is to forecast when condition ratings will change, neglecting the seriousness of the changes or the need for remedial actions. Nevertheless, a corollary issue exists: the condition ratings may be scored differently by different bridge inspectors. To a certain extent the differences may be reflected in the state indicator variables, which describe the general location and administrative jurisdiction of the bridge, because these differences change geographically among states or are attributable to inspectors drawn from different states.

\subsection{Functional Relationship between Condition and} Age

The age of each bridge is computed as 2009 minus the year of original construction. Theoretically, the rate of bridge deteriorationcan be described by polynomial function instead of linear function. This hypothesis is based on two suppositions. (1) When the bridge is deteriorated to fair condition, maintenance and repairs are implemented to keep itin acceptable condition. These improvements may slow the rate of deteriorationover time. (2) Once a bridge is in serious condition (described in Table 1) it may continue in light service, limiting the traffic loadsand making spot repairs.

A scatter plot of mean substructure ratings against age exhibits a higher-order polynomial formas shown in Fig. 5. Examination of the scatter plot in Fig. 5 shows: (1) bridge rating was highly dependent on age; (2) bridge rating exhibits a clearly higher-order polynomial relationship with age; and (3) observations for bridges of approximately the same age are very close or clustered with each other until around age 120. After age 120, the observations begin to spread out. The main reason for bridges that are over 120 year age mark a wider condition range is the result of the bridges being built before design rules of standardization. 


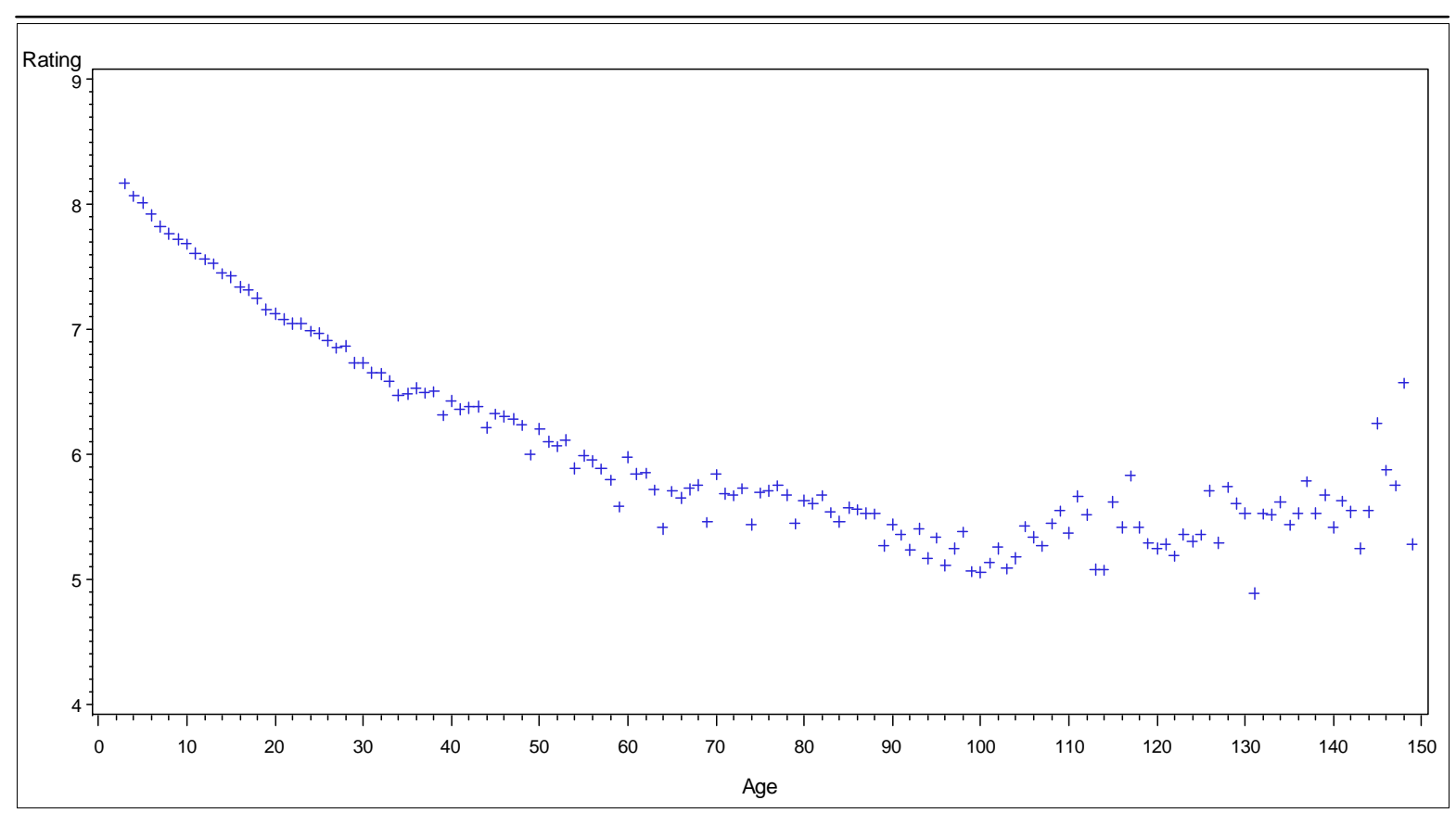

Fig. 5 Scatter plot of mean bridge substructure condition ratings and age.

While these bridges are important, the analysis is restricted to bridges $\leq 120$ years of age. Reasons for this are: (1) bridges built under bridge design standardizations should be researched separately from bridges not built to design standards, (2) bridge design standardization's effect on bridge deterioration is out the scope of the analysis, and (3) the relative high variation of bridge ratings for bridges that are more than 120 years old will jeopardize the quality of the forecasting model.

\subsection{Model Properties}

The overall results of the substructure regression model are summarized in Table 5. "F-Value" and "Prob(F)" statistics test the overall significance of the

Table 5 Regression summary for national bridge substructure model.

\begin{tabular}{|l|c|}
\hline Number of Observations Used & 409,993 \\
\hline Degrees of Freedom (DF) & 409,918 \\
\hline F-Value & $4,899.6$ \\
\hline F-Test for Model Fit (Prob(F). > F) & $<.0001$ \\
\hline R-Square & 0.4694 \\
\hline Adjusted R-Square & 0.4693 \\
\hline Coefficient of Variation & 14.29 \\
\hline
\end{tabular}

regression model. Specifically, they test the null hypothesis that "all of the regression coefficients are equal to zero." If the model explains much of the variation in condition rating, the F-Value will be large and Prob(F) will be small.

The F-value equals Mean Square Model divided by Mean Square Error (F = MSM/MSE). Where MSM equals Sum of Square for Model divided by Degree of Freedom for Model (MSM $=\mathrm{SSM} / \mathrm{DFM})$ and MSE equals Sum of Square for Error divided by Degree of Freedom for Error ( MSE = SSE/DFE). The F-Value ranges from zero to an arbitrarily large number.

The value of $\operatorname{Prob}(\mathrm{F})$ is the probability that the null hypothesis for the full model is true (i.e., all of the regression coefficients are equal to zero). In this case, an F-value is 4,900 and the Prob(F) value is $<0.0001$, which indicates a less than 1 in 10,000 chance that all of the regression parameters are zero. This would imply that at least some of the regression parameters are nonzero and that the regression equation fits the data with validity. The F-value does not indicate which variables are most significant and if all of the effects are statistically meaningful. 


\subsection{Incremental Sum of Squares Tests for Effects}

The bridge model must still be determined if the theoretical effects are statistically significant in the NBI dataset. Each variable effect is evaluated using Type I and Type III sums of squares. Type I sums of squares are called sequential sums of squares. They are computed by sequentially adding variables to a model (one at a time) and computing the reduction in the error sum of squares attributable to a particular explanatory variable. Thus, the Type I sums of squares indicate how much the residual sums of squares are reduced by adding the particular explanatory variable to the model that contains all other variables. The corresponding p-value can test the hypotheses:

$\mathrm{H}_{0}$ : the specific regression coefficient $=0$ given that no other independent variables are included in the model.

$\mathrm{H}_{\mathrm{A}}$ : the specific regression coefficient $\neq 0$ given that no other independent variables are included in the model.

A p-value that is $<0.0001$ indicates a less than 1 in 10,000 chance that the specific regression coefficient is zero given no other independent variables are included in the model.
In comparison, Type III sums of squares are called marginal sums of squares. They reflect the incremental contribution of a specific variable when it is added to a model that already includes all other variables. For this reason, Type III effects are often referred to as partial sums of squares. Thus, the Type III sums of squares indicate how much the marginal sums of squares are added when all the other independent variables are already included in the model. The corresponding p-value can test the hypotheses:

$\mathrm{H}_{0}$ : the specific regression coefficient $=0$ given that all other independent variables are included in the model.

$\mathrm{H}_{\mathrm{A}}$ : the specific regression coefficient $\neq 0$ given that all other independent variables are included in the model

A p-value that is $<0.0001$ indicates a is less than 1 in 10,000 chance that the specific regression coefficient is zero given that all other independent variables are included in the model.

As shown in Table 6, all the sum of squares tests are highly significant for the all eight main effects with p-values of $<.0001$, indicating these variables improve the explanatory power of the model.

Table 6 Incremental sum of squares tests for national bridge substructure model.

\begin{tabular}{lrrrrrr}
\hline \multirow{2}{*}{ Source } & \multicolumn{3}{c}{ Type I Sum of Squares } & \multicolumn{3}{c}{ Type III Sum of Squares } \\
\cline { 2 - 6 } & Mean Square & F-Value & Pr. > F & MeanSquare & F-Value & Pr. $>$ F \\
\hline Reconstructed & 7,395 & 8,335 & $<.0001$ & 3,088 & 3,481 & $<.0001$ \\
Bridge Material & 26,387 & 29,742 & $<.0001$ & 2,114 & 2,383 & $<.0001$ \\
Design Load & 13,116 & 14,784 & $<.0001$ & 727 & 820 & $<.0001$ \\
Structural Type & 804 & 906 & $<.0001$ & 29 & 32 & $<.0001$ \\
Operating Rating & 9,020 & 10,167 & $<.0001$ & 5,127 & 5,779 & $<.0001$ \\
Water Crossing & 740 & 834 & $<.0001$ & 274 & 308 & $<.0001$ \\
State & 861 & 970 & $<.0001$ & 640 & 721 & $<.0001$ \\
ADT & 1,140 & 1,285 & $<.0001$ & 128 & 144 & $<.0001$ \\
Age $^{2}$ & 75,764 & 85,398 & $<.0001$ & 6,332 & 7,137 & $<.0001$ \\
Age $^{2}$ & 15,926 & 17,951 & $<.0001$ & 1,177 & 1,326 & $<.0001$ \\
Age $^{3}$ & 645 & 727 & $<.0001$ & 546 & 615 & $<.0001$ \\
Age $^{4}$ & 401 & 452 & $<.0001$ & 401 & 452 & $<.0001$ \\
\hline
\end{tabular}




\subsection{Coefficient of Variation and R-Square}

The coefficient of variation (CV) is 14.29 (Table 5). It is computed by dividing the standard error of the regression by the mean value of the dependent variable $(\mathrm{CV}=\sigma / \mu)$ and multiplying by 100 to express this ratio as a percentage. The $\mathrm{CV}$ is a key indicator of the precision of a model. In this case, the $\mathrm{CV}$ is relatively low, which bodes well for prediction.

The $\mathrm{R}^{2}$ is the ratio of the sum of squares explained by the regression model to the total sum of squares. A higher $R^{2}$ is preferred, ceteris paribus. The $R^{2}$ value of 0.4694 in Table 5 means that the model explains $47 \%$ of the variation in substructure condition rating. Although the effects attributable to bridge type, design load, structural type, operating rating, traffic volume, water, and general location (i.e., state) are captured in the model, many individual bridge effects are not; This could be a reason that the model only explains $47 \%$ of the variation in substructure condition rating. The other factors that might contribute to substructure condition rating but are not included in the model can be fixed bridge effects, such as quality controls and conditions during initial construction, the inspectors, the maintenance program used, the amount of maintenance funds available, the frequency of unusual loadings, de-icing practices (e.g., how frequently the bridge has been exposed to chemicals), and effects of flooding. The reason these other factors are not included in the model is because they cannot be readily measured or the data is not readily available.

\subsection{Parameter Estimates and Standard Errors}

The estimates from the substructure model and their corresponding standard errors are shown in Table 7. As shown in Column 3, the standard errors of most variables are small in relation to the estimated values. However, the standard errors may be suspect unless the variance of the regression is consistent over the entire range of the dependent variable.

In statistics, a collection of variables is heteroscedastic if the variables do not have the same variance. The issue of non-constant variance, or heteroscedasticity, is common in regression analysis. In most instances, the form of heteroscedasticity is unknown and cannot be ascertained from the data. In such cases, the variance is said to be inconsistent, meaning it is not a function of an independent variable and does not increase or decrease monotonically. The regression coefficients (i.e., the parameter estimates) are not biased by heteroscedasticity. However, there are two potential issues. (1) Regression coefficients estimated from sample data may no longer be efficient (e.g., minimum variance estimators). (2) The standard errors may be affected. As a result, hypothesis tests may be unreliable.

The first issue is not really a concern for this study because the parameters are estimated from population data. Nevertheless, as recommended by Hayes and Cai [8], heteroscedasticity-consistent errors are used to assess thepotential effects of inconsistent variance. These standard errors (shown in Column 6 of Table 7) are computed under the assumption that the variance is not constant.

The $t$ statistic is computed by dividing the estimated value of the parameter by its standard error $(t=$ parameter estimate/standard error). This statistic is a measure of the likelihood that the actual value of the parameter is not zero. The larger the absolute value of $t$, the less likely that the actual value of the parameter could be zero. The Pr. $>|t|$ value is the probability of obtaining the estimated value of the parameter if the actual parameter value is zero. The smaller the value of $\operatorname{Pr} .>|t|$, the more significant the parameter and the less likely that actual parameter value is zero.

The values shown in Column 2, 3, 4, and 5 are the ordinary least square (OLS) regression statistics, which assume constant variance or known as homoscedasticity. The values shown in Column 6, 7, and 8 are the heteroscedasticityconsistent regression statistics, which assume non-constant variance or known as heteroscedasticityand reduce the effects of heteroscedasticityon inference by employing a heteroscedasticity-consistent standard error estimator 
Table 7 Parameter estimates and probabilities of national bridge substructure model.

\begin{tabular}{|c|c|c|c|c|c|c|c|}
\hline \multirow{2}{*}{ Variable } & \multirow{2}{*}{ Parameter Estimate } & \multirow{2}{*}{ Standard Error } & \multirow{2}{*}{ t Value } & \multirow{2}{*}{$\operatorname{Pr} .>|t|$} & \multicolumn{3}{|c|}{ Heteroscedasticity Consistent } \\
\hline & & & & & Standard Error & t Value & $\operatorname{Pr} .>|t|$ \\
\hline Intercept & 8.37624 & 0.01311 & 639.09 & $<.0001$ & 0.01192 & 702.76 & $<.0001$ \\
\hline Reconstructed & 0.28033 & 0.00475 & 59.00 & $<.0001$ & 0.00509 & 55.06 & $<.0001$ \\
\hline Water Crossing & -0.07514 & 0.00428 & -17.56 & $<.0001$ & 0.00382 & -19.65 & $<.0001$ \\
\hline \multicolumn{8}{|l|}{ Material } \\
\hline Timber & -0.49083 & 0.00758 & -64.73 & $<.0001$ & 0.00957 & -51.27 & $<.0001$ \\
\hline Steel & -0.22225 & 0.00469 & -47.34 & $<.0001$ & 0.00451 & -49.31 & $<.0001$ \\
\hline \multicolumn{8}{|l|}{ Concrete } \\
\hline \multicolumn{8}{|l|}{ Structure } \\
\hline Beam & -0.05950 & 0.00639 & -9.31 & $<.0001$ & 0.00618 & -9.62 & $<.0001$ \\
\hline Girder & -0.03618 & 0.00603 & -6.00 & $<.0001$ & 0.00555 & -6.52 & $<.0001$ \\
\hline Stringer & -0.02205 & 0.00500 & -4.41 & $<.0001$ & 0.00480 & -4.59 & $<.0001$ \\
\hline \multicolumn{8}{|l|}{ Slab } \\
\hline \multicolumn{8}{|l|}{ Design Load } \\
\hline H_10 & -0.20541 & 0.01072 & -19.16 & $<.0001$ & 0.01481 & -13.87 & $<.0001$ \\
\hline H_15 & 0.21019 & 0.00633 & 33.22 & $<.0001$ & 0.00721 & 29.17 & $<.0001$ \\
\hline H_20 & 0.28143 & 0.00688 & 40.88 & $<.0001$ & 0.00740 & 38.01 & $<.0001$ \\
\hline HS_15 & 0.27502 & 0.01119 & 24.58 & $<.0001$ & 0.01198 & 22.95 & $<.0001$ \\
\hline HS_20 & 0.36023 & 0.00540 & 66.66 & $<.0001$ & 0.00588 & 61.28 & $<.0001$ \\
\hline HS_20+ & 0.30037 & 0.00698 & 43.03 & $<.0001$ & 0.00703 & 42.71 & $<.0001$ \\
\hline HS_25 & 0.39663 & 0.00951 & 41.71 & $<.0001$ & 0.00911 & 43.55 & $<.0001$ \\
\hline \multicolumn{8}{|l|}{ Other } \\
\hline \multicolumn{8}{|l|}{ Op. Rating } \\
\hline$\leq 20$ tons & -0.94360 & 0.00727 & -129.76 & $<.0001$ & 0.01051 & -89.75 & $<.0001$ \\
\hline$\leq 30$ tons & -0.35199 & 0.00704 & -50.02 & $<.0001$ & 0.00821 & -42.89 & $<.0001$ \\
\hline$\leq 40$ tons & -0.09150 & 0.00490 & -18.69 & $<.0001$ & 0.00515 & -17.78 & $<.0001$ \\
\hline \multicolumn{8}{|l|}{$>40$ tons } \\
\hline \multicolumn{8}{|l|}{ ADT Class } \\
\hline $0-100$ & 0.08893 & 0.00686 & 12.96 & $<.0001$ & 0.00637 & 13.97 & $<.0001$ \\
\hline $101-1,000$ & 0.13321 & 0.00629 & 21.17 & $<.0001$ & 0.00560 & 23.77 & $<.0001$ \\
\hline $1,001-5,000$ & 0.09758 & 0.00615 & 15.88 & $<.0001$ & 0.00530 & 18.40 & $<.0001$ \\
\hline $5,000-19,000$ & 0.03866 & 0.00588 & 6.58 & $<.0001$ & 0.00494 & 7.83 & $<.0001$ \\
\hline \multicolumn{8}{|l|}{$>19,000$} \\
\hline Age & -0.08444 & 0.00099948 & -84.48 & $<.0001$ & 0.00093242 & -90.56 & $<.0001$ \\
\hline $\mathrm{Age}^{2}$ & 0.00139 & 0.00003811 & 36.42 & $<.0001$ & 0.00003763 & 36.89 & $<.0001$ \\
\hline $\mathrm{Age}^{3}$ & -0.00001337 & $5.390358 \mathrm{E}-7$ & -24.80 & $<.0001$ & $5.559425 \mathrm{E}-7$ & -24.04 & $<.0001$ \\
\hline $\mathrm{Age}^{4}$ & $5.33248 \mathrm{E}-8$ & $2.508156 \mathrm{E}-9$ & 21.26 & $<.0001$ & $2.68578 \mathrm{E}-9$ & 19.85 & $<.0001$ \\
\hline \multicolumn{8}{|l|}{ State } \\
\hline $\mathrm{AK}$ & -0.24860 & 0.03145 & -7.90 & $<.0001$ & 0.04357 & -5.71 & $<.0001$ \\
\hline $\mathrm{AL}$ & -0.08251 & 0.01271 & -6.49 & $<.0001$ & 0.01148 & -7.19 & $<.0001$ \\
\hline
\end{tabular}


Continued

\begin{tabular}{|c|c|c|c|c|c|c|c|}
\hline $\mathrm{AR}$ & 0.14248 & 0.01362 & 10.46 & $<.0001$ & 0.01200 & 11.87 & $<.0001$ \\
\hline $\mathrm{AZ}$ & -0.10406 & 0.01950 & -5.34 & $<.0001$ & 0.01701 & -6.12 & $<.0001$ \\
\hline $\mathrm{CO}$ & -0.19672 & 0.01126 & -17.48 & $<.0001$ & 0.00957 & -20.56 & $<.0001$ \\
\hline $\mathrm{CT}$ & -0.27745 & 0.01843 & -15.06 & $<.0001$ & 0.01595 & -17.40 & $<.0001$ \\
\hline $\mathrm{DC}$ & -0.27188 & 0.07556 & -3.60 & 0.0003 & 0.06914 & -3.93 & $<.0001$ \\
\hline $\mathrm{DE}$ & -0.46873 & 0.04080 & -11.49 & $<.0001$ & 0.03183 & -14.72 & $<.0001$ \\
\hline FL & -0.09118 & 0.01255 & -7.27 & $<.0001$ & 0.00982 & -9.28 & $<.0001$ \\
\hline GA & -0.35534 & 0.01252 & -28.39 & $<.0001$ & 0.01153 & -30.83 & $<.0001$ \\
\hline $\mathrm{HI}$ & 0.15139 & 0.03310 & 4.57 & $<.0001$ & 0.02978 & 5.08 & $<.0001$ \\
\hline IA & -0.32161 & 0.01029 & -31.26 & $<.0001$ & 0.01030 & -31.21 & $<.0001$ \\
\hline ID & -0.46769 & 0.01830 & -25.56 & $<.0001$ & 0.01977 & -23.66 & $<.0001$ \\
\hline IL & 0.05499 & 0.00988 & 5.57 & $<.0001$ & 0.00862 & 6.38 & $<.0001$ \\
\hline $\mathrm{IN}$ & -0.30917 & 0.01058 & -29.23 & $<.0001$ & 0.00915 & -33.80 & $<.0001$ \\
\hline $\mathrm{KS}$ & 0.16030 & 0.01057 & 15.17 & $<.0001$ & 0.00974 & 16.46 & $<.0001$ \\
\hline KY & -0.32335 & 0.01195 & -27.06 & $<.0001$ & 0.01112 & -29.07 & $<.0001$ \\
\hline LA & -0.28424 & 0.01203 & -23.63 & $<.0001$ & 0.01348 & -21.09 & $<.0001$ \\
\hline MA & -0.27870 & 0.01700 & -16.39 & $<.0001$ & 0.01595 & -17.47 & $<.0001$ \\
\hline MD & -0.47123 & 0.01785 & -26.39 & $<.0001$ & 0.01439 & -32.75 & $<.0001$ \\
\hline $\mathrm{ME}$ & -0.24353 & 0.02337 & -10.42 & $<.0001$ & 0.02342 & -10.40 & $<.0001$ \\
\hline MI & -0.22662 & 0.01227 & -18.47 & $<.0001$ & 0.01230 & -18.42 & $<.0001$ \\
\hline $\mathrm{MN}$ & -0.16077 & 0.01353 & -11.88 & $<.0001$ & 0.01372 & -11.72 & $<.0001$ \\
\hline $\mathrm{MO}$ & 0.34109 & 0.01044 & 32.68 & $<.0001$ & 0.00975 & 34.99 & $<.0001$ \\
\hline MS & 0.08470 & 0.01318 & 6.43 & $<.0001$ & 0.01425 & 5.94 & $<.0001$ \\
\hline MT & 0.06077 & 0.01624 & 3.74 & 0.0002 & 0.01581 & 3.84 & 0.0001 \\
\hline $\mathrm{NC}$ & -0.28434 & 0.01138 & -24.99 & $<.0001$ & 0.01068 & -26.62 & $<.0001$ \\
\hline ND & 0.04686 & 0.02071 & 2.26 & 0.0236 & 0.02401 & 1.95 & 0.0510 \\
\hline $\mathrm{NE}$ & 0.51367 & 0.01188 & 43.24 & $<.0001$ & 0.01220 & 42.09 & $<.0001$ \\
\hline $\mathrm{NH}$ & 0.17189 & 0.02415 & 7.12 & $<.0001$ & 0.02517 & 6.83 & $<.0001$ \\
\hline $\mathrm{NJ}$ & -0.30251 & 0.01504 & -20.11 & $<.0001$ & 0.01230 & -24.59 & $<.0001$ \\
\hline NM & -0.88481 & 0.02217 & -39.91 & $<.0001$ & 0.02152 & -41.12 & $<.0001$ \\
\hline $\mathrm{NV}$ & -0.26525 & 0.02359 & -11.24 & $<.0001$ & 0.01728 & -15.35 & $<.0001$ \\
\hline NY & -0.22312 & 0.01116 & -20.00 & $<.0001$ & 0.01116 & -19.99 & $<.0001$ \\
\hline $\mathrm{OH}$ & 0.04124 & 0.00945 & 4.36 & $<.0001$ & 0.00878 & 4.70 & $<.0001$ \\
\hline OK & -0.72676 & 0.01076 & -67.56 & $<.0001$ & 0.01159 & -62.72 & $<.0001$ \\
\hline OR & -0.30992 & 0.01411 & -21.96 & $<.0001$ & 0.01427 & -21.72 & $<.0001$ \\
\hline $\mathrm{PA}$ & -0.79479 & 0.01156 & -68.76 & $<.0001$ & 0.01152 & -69.00 & $<.0001$ \\
\hline RI & -0.95154 & 0.04017 & -23.69 & $<.0001$ & 0.04058 & -23.45 & $<.0001$ \\
\hline $\mathrm{SC}$ & -0.40671 & 0.01322 & -30.77 & $<.0001$ & 0.01265 & -32.16 & $<.0001$ \\
\hline SD & -0.51615 & 0.01640 & -31.48 & $<.0001$ & 0.01621 & -31.84 & $<.0001$ \\
\hline TX & -0.41609 & 0.00912 & -45.65 & $<.0001$ & 0.00755 & -55.15 & $<.0001$ \\
\hline UT & -0.11995 & 0.02257 & -5.31 & $<.0001$ & 0.01986 & -6.04 & $<.0001$ \\
\hline VA & -0.34138 & 0.01213 & -28.15 & $<.0001$ & 0.01112 & -30.71 & $<.0001$ \\
\hline
\end{tabular}


Continued

\begin{tabular}{|c|c|c|c|c|c|c|c|}
\hline VT & -0.00301 & 0.02123 & -0.14 & 0.8873 & 0.02206 & -0.14 & 0.8915 \\
\hline WA & -0.07969 & 0.01416 & -5.63 & $<.0001$ & 0.01236 & -6.45 & $<.0001$ \\
\hline WI & -0.17566 & 0.01157 & -15.18 & $<.0001$ & 0.01031 & -17.03 & $<.0001$ \\
\hline WV & -0.29327 & 0.01507 & -19.47 & $<.0001$ & 0.01473 & -19.91 & $<.0001$ \\
\hline WY & -0.34206 & 0.02055 & -16.65 & $<.0001$ & 0.01841 & -18.58 & $<.0001$ \\
\hline CA & & & & & & & \\
\hline
\end{tabular}

of OLS parameter estimates. A comparison of Columns 4 and 7 shows only modest differences between the $t$ values, suggesting mild inconsistency. Onlyone of the hypothesis tests is affected, based ona probability threshold of 0.05 .

\subsection{Probability Values and Inferences}

The NBI database constitutes the inventory or population of publicly-owned bridges in the United States. Because an inventory is available, sampling variability is not an issue. Nevertheless, it is beneficial to envision the NBI as a large sample of bridges that do (or could) exist. This visualization allows hypothesis tests that provide intuitive insights concerning the statistical significance of particular effects. For each variable, the null hypothesis is that the partial effect attributable to the variable is statistically insignificant. This means that the intercept shift attributable to the variable is not significantly different from zero. For quantitative variables, the null hypothesis is that the partial slope coefficients are not significantly different from zero.

The probability values (or p-values) associated with the $t$ statistics are shown in Columns 5 and 8 of Table 7 , respectively. With two exceptions, the p-values in Column 8 indicate that the estimated independent variables' parameters are highly significant and are not equal to zero (i.e., values of $<.01$ ). The $p$-values of 71 of the variables in the model are $<0.0001$, indicatingless than a 1 in 10,000 chance of observing $t$ values as large as those observed. However, the large p-value of 0.89 for Vermont (variable name is coded as VT) indicates that the intercept for this state is not significantly different from the model intercept, which implies that the interceptsofVermont and California (the state left out of the model) are not statistically different. The p-value of 0.051 for North Dakota is marginally significant (i.e., $<0.10$ ).

As shown in Table 7, the parameter estimates of Age, $\mathrm{Age}^{2}, \mathrm{Age}^{3}$, and $\mathrm{Age}^{4}$ are highly significant. If any of the terms of the polynomial were unimportant, the probability values associated with the tratios would be much higher. The negative sign of age indicates that bridge condition rating decreases with age. The positive sign of age squared indicates that the rate of deterioration is not linear and will slow with age - i.e., when bridges reach advanced ages, such as 65 . The negative and positive signs associated with $\mathrm{Age}^{3}$ and $\mathrm{Age}^{4}$ indicate that the regression surface turns up and down again, as illustrated in Fig. 5.

\subsection{Class Variable Effects}

In this section, the interpretation of the estimated parameters associated with material, structural typestructural, design load, operation rating, and an ADT class is introduced.

In the regression model, the effect of a class level is interpreted in relation to the base level subsumed in the intercept. As shown in Table 7, the parameter estimates of steel, timber, and other bridges have negativesigns, indicating that these bridges deteriorate at faster rates than concrete bridges (ceteris paribus). Moreover, the larger negative coefficient of timber indicates that the expected condition ratings of timber bridges are lower than the expected condition ratings of steel bridges. These results are consistent with the findings of Dunker and Rabbat [6]. 
The coefficients of stringer, tee-beam, and boxgirder bridges are negative in relation to slab bridges, indicating that slab bridges are expected to have higher condition ratings than other types of structures. These results are consistent with the findings of Kim and Yoon [5].

The coefficients of H-15, H-20, HS-15, HS-20, $\mathrm{HS}-20^{+}$, and HS-25 bridges are positive, meaning that substructure ratings should be higher over time for these designs than for bridges included in the "other" category. The greatest positive effects are associated with HS-25, HS-20, and HS- $20^{+}$bridges, respectively. The only negative sign is associated with H-10, which indicates that these bridges (which have the lowest load ratings) are expected to deteriorate at faster rates than bridges included in the "other" category.

The signs of the operating rating variablesare negative and must be interpreted in relation to bridges with operating ratings $>40$ tons. The negative signs suggest that bridge substructure rating is expected to decrease with operating rating. This is because the operating rating is a reflection of the capability of a bridge to accommodate modern truck traffic. The relative magnitudes of the coefficients make sense too, because the magnitudes of the effects increase as the operating ratings decline. However, the difference between bridges with operating ratings of 30.1 to 40 tons and bridges with operating ratings $>40$ tons is relatively small.

The signs of the ADT class variables (0-100; 101-1,000; 1,001-5,000; and 5001-19,000 vehicles per day) are positive in relation to the base level ( $>$ 19,000 vehicles per day), suggesting that traffic contributes to loss of condition rating over time. Similarly, the negative sign of waterspan indicates that exposure of bridge piers and foundations to water results in lower predicted values of condition. However, the positive sign of reconstruction indicates that, after reconstruction, a bridge's condition rating jumps. In the regression model, this effect is reflectedin the intercept shift attributable to reconstruction.

\subsection{Multicollinearity}

Multicollinearity exists when one or more of the independent variables are highly correlated with each other. In multiple regression analysis, multicollinearity is a question of degree. However, extensive multicollinearity may create issues. (1) The standard errors of the estimates may become inflated. As a result, hypothesis tests may be unreliable. Because of inflated errors, a variable that is actually important may fail a hypothesis test. (2) The estimates of the parameters may be conditional upon other variables. Consequently, the parameter estimates of several variables may change if a highly correlated variable is dropped from or added to the model.

Multicollinearitycan be assessed throughthe variance inflation factor (VIF), which is computed by regressing one independent variable against all others and using the $\mathrm{R}^{2}$ from that regression. Opinions vary widely about in what degree ofmulticollinearity can be tolerated. One suggestion is that variables with VIFs greater than 10 may indicate problems. Other, more conservative ideas, suggest that VIFs greater than 5.0 should be investigated. The VIF scores of the 70 independent variables associated with the eight effects range from 1.01 to 4.18 with a median value of 1.48 , suggesting relatively low levels of multicollinearity. As shown in Table 8, the parameter estimate of age is relatively robust with respect to the dropping or exclusion of effects.

As shown in Table 7, the coefficient of age is -0.08444. For purposes of comparison, revised estimates of age after dropping the main effects one at a

Table 8 Sensitivity of age to main effect variables.

\begin{tabular}{lll}
\hline Excluded Effect & $\begin{array}{l}\text { Parameter } \\
\text { of Age }\end{array}$ & $\begin{array}{c}\text { Estimate Percent Change in } \\
\text { Estimate }\end{array}$ \\
\hline State & -0.08430 & $-0.2 \%$ \\
Design Load & -0.08401 & $-0.5 \%$ \\
Bridge Material & -0.08342 & $-1.2 \%$ \\
ADT Class & -0.08402 & $-0.5 \%$ \\
Operating Rating & -0.08182 & $-3.1 \%$ \\
Structural Type & -0.08471 & $0.3 \%$ \\
\hline
\end{tabular}


time are shown in Column 2 of Table 8 . The percentage change as a result of each dropped effect is listed in Column 3. As the table shows, the largest change would occur if the operating ratingis dropped from the model. Perhaps this is because very old bridges tend to have lower operating ratings. The second largest change would result from dropping bridge material, suggesting there is some collinearitybetween the age of structures and the material used. This could be attributable to a shift in construction materials over time from timber to concrete and steel.

The main inferences from these illustrations are (1) without controlling for operating rating and bridge material, the parameter estimate of age would be biased, and (2) multicollinearity is relatively low, making the estimate of age somewhat robust. The practical inference of this discussion is that none of the variables should be dropped from the model because, in doing so, information would be lost.In general, the omission of relevant variables results in biased coefficient estimates for the explanatory variables left in the model [9].

\subsection{Model Forecast}

Because the predictions are ratio scaled, they include fractional results. In effect, they provide information about when a bridge is in transition from one condition level to the next. For example, a bridge with a predicted condition rating of 6.8 is likely to stay in satisfactory condition for several years. In contrast, a bridge with a predicted condition rating of 6.05 is on the verge of transitioning from satisfactory to fair.

All of the indicator variables must be included in a forecast because the effect attributable to a coefficient (e.g., H-20 bridges) reflects all of the base levels of the other indicator variables subsumed in the intercept e.g., a concrete slab bridge in California with an operating rating $>40$ tons that has not been reconstructed and does notspan water. If the levels of any of the indicator variables change from their bases, these effects must be included in the forecast. For example, if an $\mathrm{H}-20$ bridge is built with steel, the coefficients of H-20 and steel must be added to the intercept to create an adjusted intercept. The forecasting process is illustrated for an HS-20 box girder steel bridge in New York that has never been reconstructed, spans a body of water, has an operating rating $>40$ tons,and average daily traffic of 15,000 vehicles. The specific intercept is computed as $8.37624-0.07514-0.22225-0.03618+0.36023+$ $0.03866-0.22312 \approx 8.22$. Seven terms are reflected in this calculation: the model intercept (8.37624), the New York intercept shift (-0.22312), the material type intercept shift (-0.22225), the bridge design intercept shift (0.36023), the structure intercept shift (-0.03618), the water crossing intercept shift (-0.07514) and the ADT intercept shift (0.03866). There is no adjustment factor or shift for operating rating. This is because operating rating of $>40$ tons serves as the base operating rating of the model. Moreover, there is no intercept shift for reconstruction.

In this process, the parameter estimate of each class variable is added to the intercept to compute a specific intercept for the type and design of bridge and traffic class within the state of interest. In this example, a new HS-20 steel bridge is predicted to have a condition rating of 6.35 after 40 years. In other words, the bridge is expected to be in satisfactory condition with only minor problems. The condition ratings over time for this example are shown in Fig. 6.

The change in substructure condition can be estimated for small changes in age by taking the partial derivative of the function. However, the rate of bridge deterioration during any year is relatively small. Instead of using the derivative, Fig. 7 shows the projected rates of condition loss for bridges by decade from 10 to 100 years, as estimated from the model. The chart resembles a portion of the curve shown earlier in Fig. 5. Because of the polynomial form, the rate of condition loss varies with age. A bridge loses 0.52 rating points during the second decade of existence. However, the rate of loss drops to $0.37,0.27$, and 0.21 in the third, fourth, and fifth decades, respectively. The expected rates of decline are $0.17,0.11$, and 0.08 for 


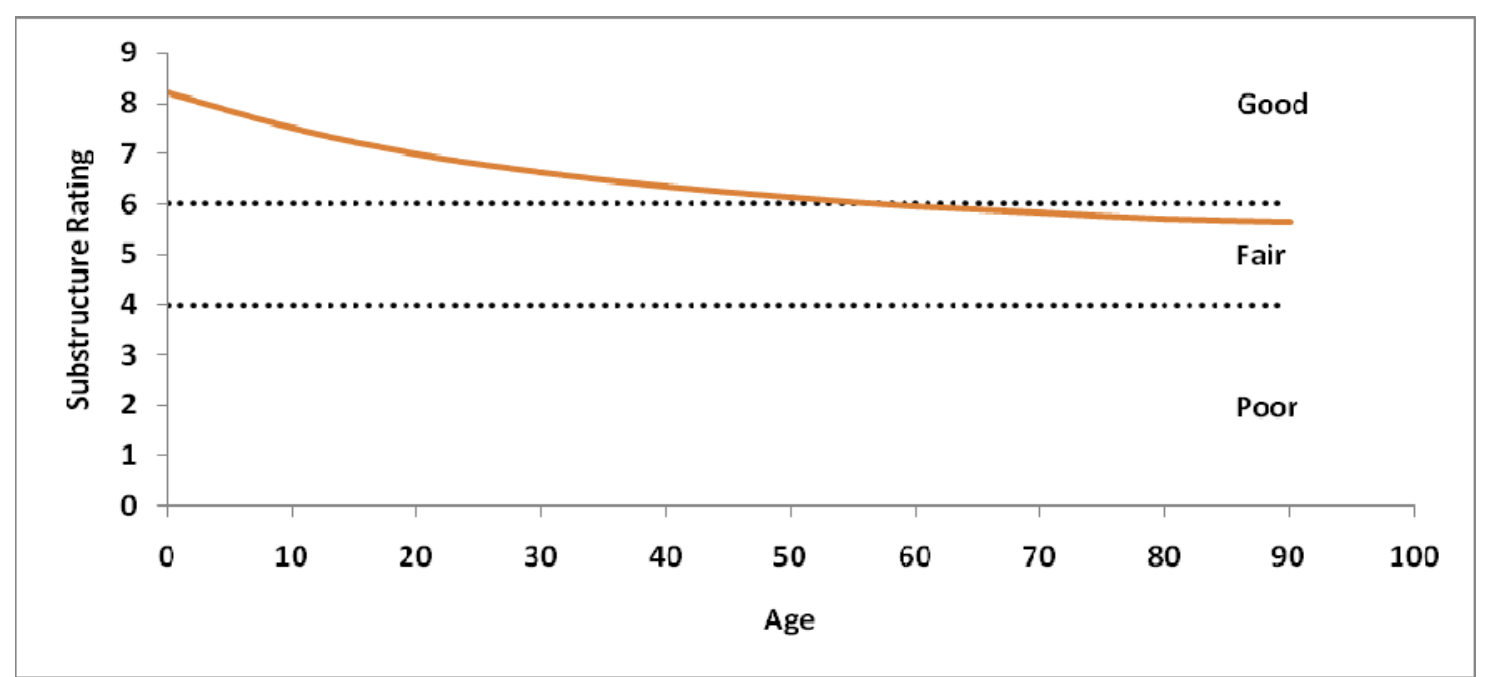

Fig. 6 Substructure ratings versus age for HS-20 Box Girder Steel Bridge in New York.

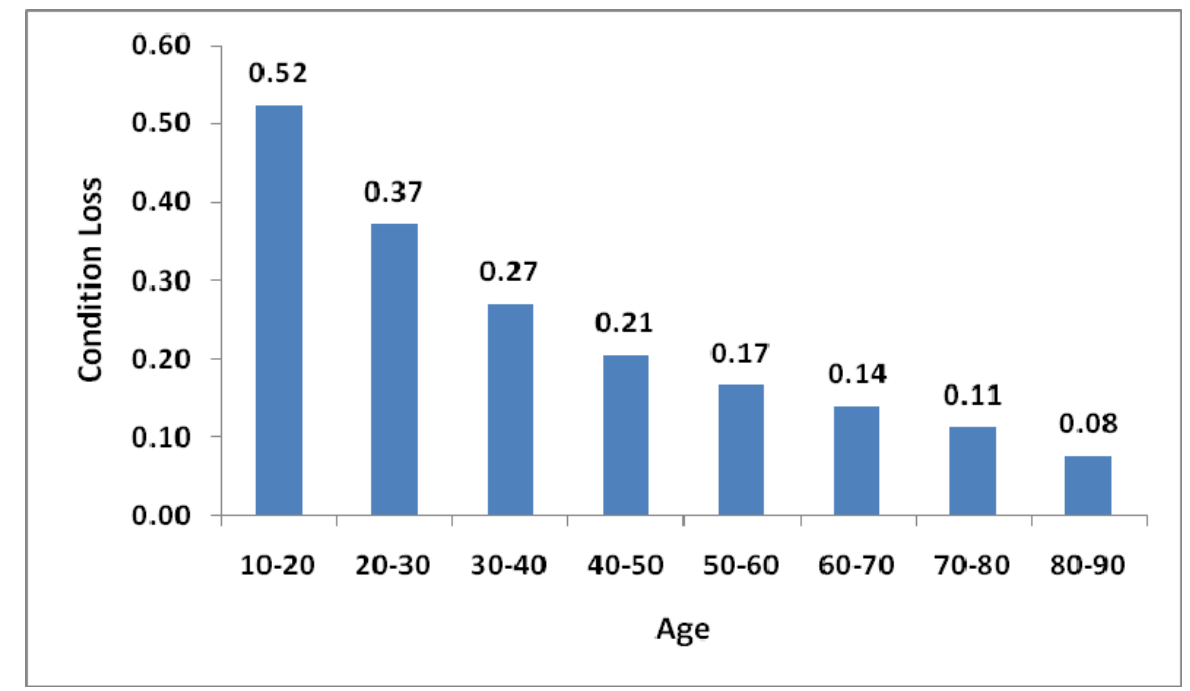

Fig. 7 Rate of expected bridge substructure condition loss by decade.

bridges in their sixth, seventh, and eighth decades of life, respectively.

\section{State-Level Model}

While the national model could be used to forecast condition ratings within a particular state, its primary value is to provide strategic information for policy and funding considerations. More specific forecasts of bridge conditions can be derived from a state-level model, which is illustrated for Iowa - a state located in the north-central region of the United States.

As would be the case with any state, Iowa has some unique characteristics that warrant adjustments to the national model. Only four of Iowa's bridges are in the HS- 25 category. These observations are deleted due to insufficient numbers. Less than $0.5 \%$ of the observations fall into the H-10 and H-15 categories. For statistical reasons, these classifications are combined into one category. The traffic levels are much lower in Iowa than in more populatedregions. Approximately $50 \%$ percent of the bridges carry less than 60 vehicles per day. Given the large percentage of bridges with low traffic volumes, ADT is highly collinear with other variables and has a weak effect. Therefore, it is dropped from the model. In addition, the highway district variable is substituted for the state 
indicator. With these modifications, the remaining variables are the same as in the national model. Although the F-tests for the remaining effects are highly significant, a third-order polynomial fits the Iowa data better than a fourth-order model.

With an $\mathrm{R}^{2}$ of 0.637 , the Iowa model explains nearly $64 \%$ of the variation in substructure condition rating withinthe state. As shown in Table 9, all but two of the variables in the model are statistically significant with p-values of $<0.05$, including the sub-state district variables. The VIF scores of the effect variables range from 1.02 to 3.09 with a median value of 1.79 . The exclusion ofADT from the model drops the $\mathrm{R}^{2}$ slightly, from 0.6376 to 0.6370 , indicating that traffic is not a significant explanatory variable, given the high proportion of bridges with low traffic volumes.

The signs of the design load categories are all positive. As expected, HS-20 and HS- $20^{+}$bridges show the greatest increases in condition ratings relative to other bridges, and the coefficient of $\mathrm{H}-20$ bridges is

Table 9 Parameter Estimates and Probabilities of Iowa Bridge Substructure Model.

\begin{tabular}{|c|c|c|c|c|}
\hline Variable & Parameter Estimate & Standard Error & t Value & $\operatorname{Pr} .>|t|$ \\
\hline Water Crossing & -0.12521 & 0.02969 & -4.22 & $<.0001$ \\
\hline \multicolumn{5}{|l|}{ Material } \\
\hline Timber & -0.50655 & 0.02928 & -17.30 & $<.0001$ \\
\hline Steel & -0.24036 & 0.02237 & -10.74 & $<.0001$ \\
\hline \multicolumn{5}{|l|}{ Concrete } \\
\hline \multicolumn{5}{|l|}{ Structural Type } \\
\hline Beam & -0.43045 & 0.03350 & -12.85 & $<.0001$ \\
\hline Stringer & -0.00281 & 0.02226 & -0.13 & 0.8995 \\
\hline \multicolumn{5}{|l|}{ Slab } \\
\hline \multicolumn{5}{|l|}{ Design Load } \\
\hline H-10/H-15 & 0.22460 & 0.02449 & 9.17 & $<.0001$ \\
\hline $\mathrm{H}-20$ & 0.39009 & 0.02722 & 14.33 & $<.0001$ \\
\hline HS-15 & 0.36686 & 0.11538 & 3.18 & 0.0015 \\
\hline HS-20 & 0.51128 & 0.02743 & 18.64 & $<.0001$ \\
\hline HS- $20^{+}$ & 0.71507 & 0.07222 & 9.90 & $<.0001$ \\
\hline \multicolumn{5}{|l|}{ Other } \\
\hline \multicolumn{5}{|l|}{ Op. Rating } \\
\hline$\leq 20$ tons & -1.20902 & 0.03235 & -37.38 & $<.0001$ \\
\hline$\leq 30$ tons & -0.40276 & 0.02688 & -14.98 & $<.0001$ \\
\hline$\leq 40$ tons & -0.01122 & 0.02010 & -0.56 & 0.5769 \\
\hline \multicolumn{5}{|l|}{$>40$ tons } \\
\hline Age & -0.10687 & 0.00243 & -43.99 & $<.0001$ \\
\hline $\mathrm{Age}^{2}$ & 0.00107 & 0.00005336 & 20.12 & $<.0001$ \\
\hline $\mathrm{Age}^{3}$ & -0.00000347 & $3.238061 \mathrm{E}-7$ & -10.72 & $<.0001$ \\
\hline \multicolumn{5}{|l|}{ District } \\
\hline \multicolumn{5}{|l|}{1} \\
\hline 2 & 0.06306 & 0.02602 & 2.42 & 0.0154 \\
\hline 3 & 0.14217 & 0.02596 & 5.48 & $<.0001$ \\
\hline 4 & -0.17984 & 0.02606 & -6.90 & $<.0001$ \\
\hline 5 & -0.16648 & 0.02697 & -6.17 & $<.0001$ \\
\hline 6 & 0.14587 & 0.02704 & 5.39 & $<.0001$ \\
\hline
\end{tabular}


greater than the coefficient of $\mathrm{H}-10 / \mathrm{H}-15$ bridges. The coefficients of timber and steel are similar to the coefficients of those variables in the national model. In addition, the signs of structural type and operating rating are the same as in the national model; however, "stringer" is not statistically significant, indicating that the intercepts for stringer and slab bridges in Iowa are essentially the same. Moreover, there is no significant difference between bridges with operating ratings of 30.1 tons to 40 tons and bridges with operating ratings $>40$ tons.

In the national model, the state variable controls for climatic, geographic, political, financial, and jurisdictional differences among states. At the state level, the highway district indicator variable serves a similar purpose, controlling for variations within the state. While temperature and moisture may vary within a state, the differences are relatively small compared to variations ona national scale. The advantage of the state model is homogeneity of conditions.

\section{Conclusion}

A national model for estimating substructure deterioration rates has been developed which has good statistical properties: e.g., a large F-value with many highly significant parameters, low multicollinearity, very mild heteroscedasticity, and a relatively low coefficient of variation. This model is appropriate for system and subsystem planning, in which the objective is to provide agency managers and policy makers with strategic information: e.g., the expected condition levels of subsets of bridges. However, a more specific forecasting model can be developed for each state using NBI data and the procedures described in this paper. However, in doing so, some adjustments to category levels and variables may be necessary. At the state level, it is possible to supplement NBI data with local climate data from nearby weather stations [5], which may reflect local climatological differences more specifically than the highway district indicator variable.
The relationship between age and substructure condition is a fourth-order polynomial. Some of thekey findings are (1) a bridge substructure is expected to lose from 0.52 to 0.11 rating points per decade as it ages from 10 to 70 years; (2) levels of deterioration increase significantly as the material changes from concrete, to steel, to timber; (3) slab bridges have lower levels of deterioration than other structures; (4) bridges that span water have lower condition ratings; (5) bridges with higher operating ratings have higher condition ratings; and (6) substructure condition ratings vary significantly among states.

In conclusion, it is important to summarize some of the key assumptions and information not available for this study. (1) The history and timing of maintenance expenditures for the life of each bridge are unknown. (2) The condition ratings are scored by different people. As a result, human variations are reflected in the evaluations.(3) Many individual bridge effects, such as the frequency of unusual loadings, deicing practices, and initial and extreme conditions are not reflected in the models.(4) Because only current ADT values are known, traffic is treated as a categorical (rather than a continuous) variable. Nevertheless, the ADT classification of a bridge may have shiftedover time as a result of very large traffic changes. (5) The analysis includes only stringer, tee-beam, slab, boxgirder, concrete, timber, and steel bridges, while excluding culverts. (6) The results are specific to the types of bridges analyzed.

\section{References}

[1] United States Department of Transportation (USDOT), 2008 Status of the Nation's Highways, Bridges, and Transit: Performance Report to Congress, Washington, D.C., 2010 .

[2] American Society of Civil Engineers (ASCE), 2009 Infrastructure Fact Sheet, Washington, D.C., 2009.

[3] M. Jiang and K. C. Sinha, Bridge service life prediction model using the markov chain, Transportation Research Records 1223, Transportation Research Board, Washington, D.C., 1989. 
[4] M. J. Kallen and J. M. Van Noortwijk, Statistical inference for markov deterioration models of bridge conditions in the Netherlands, in: P. J. Cruz, D. M. Frangopol and L. C. Neves, Bridge Maintenance, Safety, Management, Life-Cycle Performance and Cost: Proceedings of the Third International Conference on Bridge Maintenance, Safety and Management, 16-19 July, Porto, Portugal, London, Taylor \& Francis, 2006, pp. 535-536.

[5] Y. J. Kim and D. K. Yoon, Identifying critical sources of bridge deterioration in cold regions through the constructed bridges in North Dakota, Journal of Bridge Engineering, October, 2010.

[6] K. F. Dunker and B. G. Rabbat, Highway bridge type and performance patterns, Journal of Performance of Constructed Facilities 4 (3) (1990) 161-173.
[7] S. M. Madanat, M. G. Karlaftis and P. S. McCarthy, Probabilistic infrastructure deterioration models with panel data, Journal of Infrastructure Systems, March, 1997.

[8] A. F. Hayes and L. Cai, Using heteroskedasticity-consistent standard error estimators in ols regression: An introduction and software implementation, Behavior Research Methods 39 (4) (2007) 709-722.

[9] W. H. Greene, Econometric Analysis. Pearson-Prentice Hall, New Jersey, 2008. 